article traces the historical development of methods of measuring distance by means of radio waves using both the frequency modulation and amplitude modulation or pulse methods. It is now about twenty years since the classical experiments of Appleton and Barnett provided a direct measurement of the height of the reflecting layer in the ionosphere using the frequency variation method; while, shortly afterwards, Breit and Ture demonstrated the use of short trains of waves of about one millisecond in lengih for making the same type of measurement. Many variations and improvements on these two methods have been made from time to time by those engaged in studying the properties of the ionosphere as a medium for reflecting radio waves back to the earth's surface. Methods based on the same principles have also been used for determining the altitude of aeroplanes by reflecting waves from the ground beneath: The article referred to above describes briefly the various methods which have been devised to meet these applications by the aid of a review of the published scientific literature, and especially of the publications of the United States Patent Office for the past ten years or so. As the author states, the notes are necessarily incomplete for the war period, on account of the scarcity of publications for security reasons. The bibliography of eighty-one references appended to the article may, however, be useful to those concerned with tracing the historical development of a comparatively modern application of radio science.

\section{Institute of Ophthalmology at the Royal Eye Hospital}

THE immense clinical material and the considerable research activities at the Royal Eye Hospital have prompted the Council of the Hospital to initiate the establishment of an Institute of Ophthalmology, where teaching and research can be carried out systematically and co-ordinated with the work of laboratories and of other ophthalmic and of general hospitals. The Institute will have an independent Board of Governors; and panels of scientific, medical, surgical and ophthalmic advisers have been set up to help in planning and carrying out the work. The Institute will be open to all ophthalmologists, and offers of co-operation will be welcomed.

\section{Beit Memorial Fellowships for Medical Research}

THE following elections have been made to Beit Memorial Fellowships for Medical Research, with permission for each fellow to be seconded at any time for war duties: Fourth Year Fellowships (£500 a year): Dr. W. Holmes, to continue the study of the regeneration of nerve fibres after injury (Department of Zoology and Comparative Anatomy, University Museum, Oxford); Dr. Mary F. Lockett, to continue the study of renal pressor substances responsible for experimental high blood pressure (Pharmacology Laboratory, Cambridge). Junior Fellowships ( $£ 400$ a year): Dr. J. C. Boursnell, to study the fate and functions of trace and some other elements in the animal body, using radioactive isotopes (Department of Biochemistry and Chemistry, Medical College of St. Bartholomew's Hospital); Dr. G. A. Levvy, to study the adaptive enzymes in the animal body with special reference to the role of glucuronidase in the metabolism of steroid hormones and related substances (Depart. ment of Biochemistry, University of Edinburgh);
Dr. H. J. Rogers, to study the biochemistry of hyaluronidase obtained from various sources, and the role of enzymes such as hyaluronidase and lecithinase and other bacterial antigens in infection (Lister Institute, Elstree, Herts); Dr. G. J. Romanes, to study the relationship between the developing mesoderm and the motor apparatus of the spinal cord supplying it (Department of Anatomy, University of Cambridge); Dr. F. Sanger, to study the chemical structure of proteins with special reference to insulin (Sir William Dunn Institute of Biochemistry, Cambridge); Miss S. P. V. Sherlock, to study the hepatic function in disease by biopsy methods (Department of Medicine, British Postgraduate Medical School); Dr. Charity Waymouth, to study the factors influencing tissue growth in vitro (Physiology Department, University of Aberdeen); Mr. E. C. Webb, to study the ultimate mode of action of drugs and poisons in living tissues (Sir William Dunn Institute of Biochemistry, Cambridge).

The Trustees, in their annual report for the year 1943-44, refer to the election this year of Prof. G. F. Marrian, professor of biochemistry in the University of Edinburgh (fellow 1917-20), to the fellowship of the Royal Society. They accepted with great regret the resignation of Prof. T. R. Elliott, who has been secretary to the Advisory Board since 1930, and whose experience and wisdom had been of inestim. able value; his place on the Board has been taken by Sir Thomas Lewis, and Dr. A. N. Drury, director of the Lister Institute, has been appointed acting secretary.

\section{Announcements}

Dr. Norman Allen, of the Research and Development Laboratory of the Mond Nickel Company, Ltd., has been appointed superintendent of the Metallurgy Division at the National Physical Laboratory. He will take up his duties on September 1,1944 .

TнЕ honorary degree of doctor of science has been conferred by Columbia University, New, York, on Dr. L. J. Briggs, director of the U.S. Bureau of Standards, and Te-Pang Hou, who was trained first in China and afterwards in the United States, and eventually established in China a modern chemical work.

The Royal Institution has established nine graduate memberships, three of which will be awarded annually to recent graduates, of either sex, of any university in the Britich Empire who have taken a degree with either first or second class honours in any scientific subject. The membership will give the holder the full privileges of members of the Royal Institution for a period of three years, with the exception of the right to attend or vote at any meeting of the members. The first three graduate memberships will be awarded about November 1944 to students who have graduated in 1944. Application forms can be obtained from the General Secretary, Royal Institution, 21 Albemarle Street, London, W.1.

ERratum. In the communication " 'Fluorine-like' Action of Various Substances on the Teeth" by Prof. J. T. Irving, in Nature of July 29, last paragraph but one (p. 150), line 17, the word "not" should be omitted, and the phrase should read ". . . the other substances hөre examined also act only by altering the composition of the blood ...." 